\title{
Traditional Healers and Traditional Healing among Ilika Tribes in Garmsar, Iran
}

\author{
Shideh Parnian \\ Department of Anthropology, Garmsar Branch, Islamic Azad University \\ Garmsar, Iran \\ Shahram Kiaei (Corresponding author) \\ Department of English, Qom Branch, Islamic Azad University \\ Qom, Iran \\ E-mail: shahramkiaei@yahoo.com
}

Received: December 15, 2013 Accepted: December 17, 2013 Published: January 20, 2014

doi:10.5296/ijch.v1i1.4896 URL: http://dx.doi.org/10.5296/ijch.v1i1.4896

\begin{abstract}
This paper focuses on traditional healers and traditional healing practices and processes particularly among the contemporary Ilika tribes of Garmsar, Iran. It is written both out of the desire to know and explore the beauty of traditional healing. By the time we had written this paper, we had already had a five-year relationship with the people of Garmsar since we are still teaching anthropology courses in that zone. We realize that we may always be beginning students of Iranian culture especially those related to the dry lands of Iran, including Garmsar. Nevertheless, our attraction to this project was based on the desire to share what we have learned in a way that can help native and indigenous people by portraying the outsiders a cross-cultural understanding on Ilika people. The purpose and the goal of the present anthropological research is to develop a comprehensive understanding of traditional healing process that Ilika tribe people employed and still use relatively for the treatment of different types of illnesses. It was also important to explore the experiences of practitioners of traditional healing because there continues to be a lack of literature on this subject. Furthermore, among the Ilika tribe people themselves, shows that there are significantly lack of understanding, awareness and exposure towards the importance of preserving traditional healing knowledge and traditions.
\end{abstract}

Keywords: Ilika, Healing, Healer, Traditional 


\section{Mll Macrothink}

\section{Background of the Study}

Ilika tribe people follow Islam. They follow all the rules and regulations, which are ordered in Islam to be done. The reason why we are relating Ilika tribe's religion religion to our paper is that majority of healing processes among Ilika tribe people are in close contact with their religion.

Although modern medicines are used widely nowadays, the use of traditional medicine is still being practised by Iranians especially Ilika people. The major tribe of dry lands in is called Ilika (Qome Ilikaee) mostly resides here who has less contact with modern technology. For the Iranian people, their native treatments are their only hope to save their lives and their youngsters against any diseases and illness which most of the time threatens them to death. It appears that the current government which based on modern way of thinking and facilities disregards their needs and their beliefs. As a result, Iranian people misunderstood medical anthropology. They frequently assume that medical anthropologists are just on some kind of excavations like archaeologists. They just see them as a subject for their discoveries and experimentations.

Iranian definition of traditional medicine is an art which pays attention to the body and makes the body healthy. Their traditional doctors divided medicine in two parts. The first one is theoretical medicine which consists of fundamental science required for every doctors to recognize the whole situation of the patients. The second one is called Practical Medicine which is required to be taught in the class by which they could prescribe medicine for a patient. This medical practice is commonly referred to as first aid.

The Semnan Province in Garmsar is among the dry lands in Iran which consist of among the largest number of traditional healers and treatments. They perform unofficial medical practices yet they are frequently consulted and trusted by their patients for their therapeutic methods. There are different types of traditional treatments in Iran performed by the traditional healers. Some of these are the following: herbal therapy, massage therapy, leech therapy, and cupping. The following map that is one of the comprehensive maps of Iran shows the number of provinces in this country and the capital cities of provinces in details. It also shows the neighbouring countries, which include Afghanistan, Pakistan, Soviet Union, Turkey, Iraq and Kuwait. These countries have many similarities and dissimilarities with Iran concerning weather and people. But what is important in this thesis is that I focus on the dry lands of Iran, especially Semnan province and one of its small cities, which is called Garmsar, and among tribes who live there and are called Ilika people. The other aspects except traditional healing among the area of Garmsar are ignored and we concentrate on traditional healing and healers of Garmsar. 


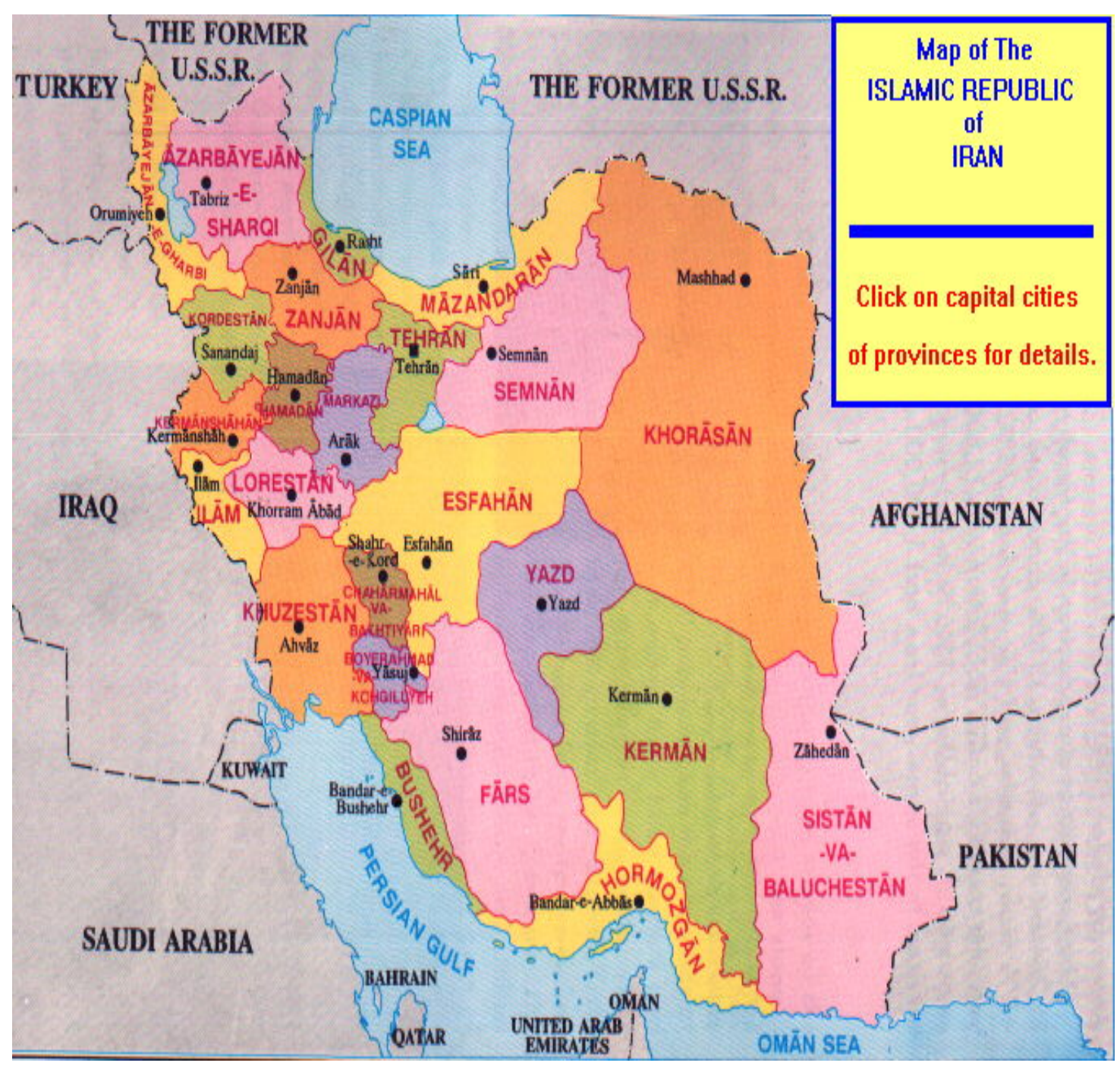

Figure 1. A comprehensive map of Iran

The following map shows the area of Garmsar which is a very small area and not many people live there. As it was explained, Ilika people live in this small area and what we studied about and discussed happened in this area. 


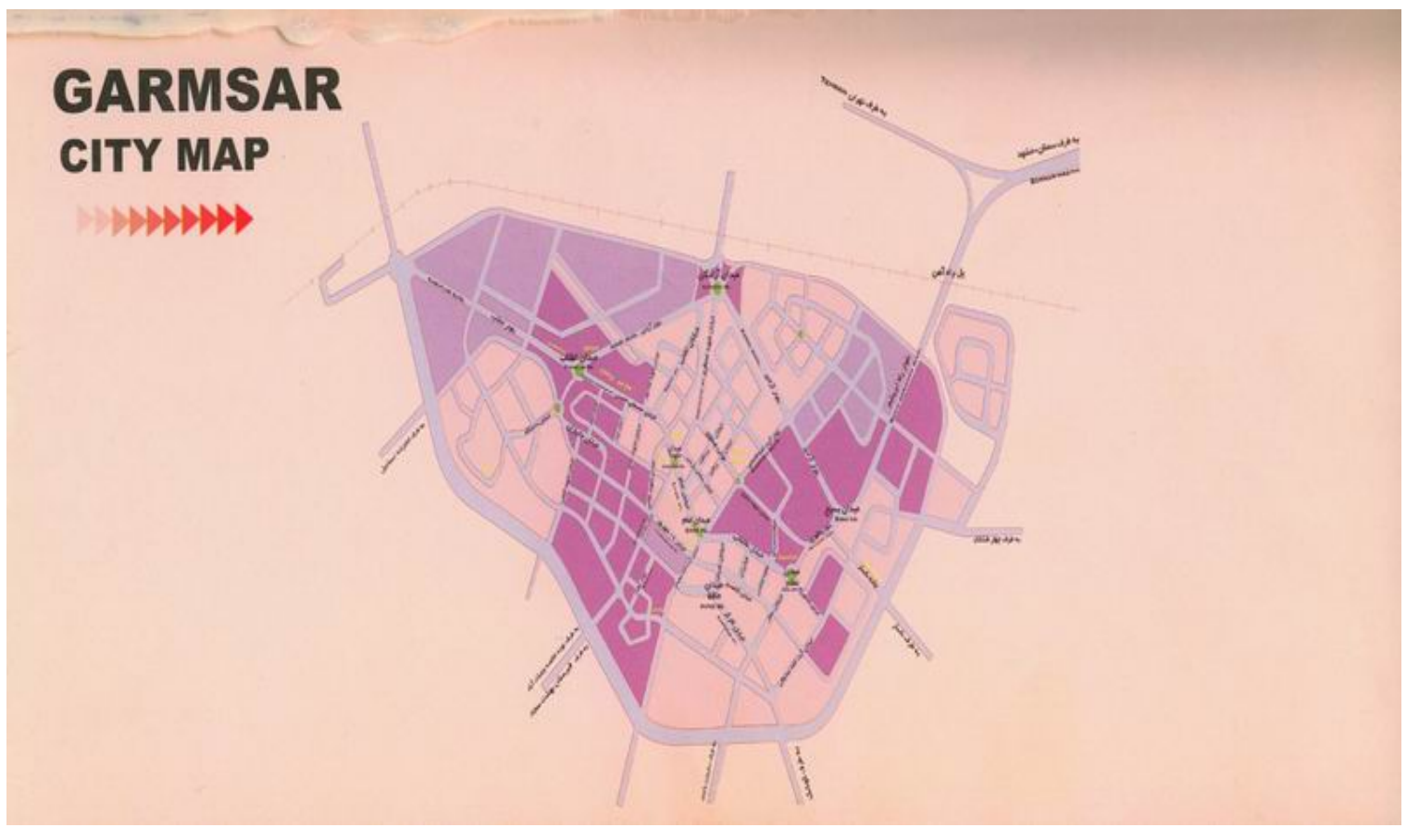

Figure 2. City map of Garmsar (Semnan Province)

Moreover, there are different reasons why Iranians use traditional healing and medicine. One of the reasons is that traditional healing and medicine are accessible, comfortable and easy to practise compared to modern medicine. The second important reason is that those who prefer using traditional medicine and healing over modern medicine are quite close with the healers and think them as a person who is living in the same society from which they have come. Most of those healers are also living in the same area in which the others live. This second reason is the cause of the Ilika tribes' preference to refer to traditional healing and healers. The third reason is that people of Ilika tribes are poor and traditional healers charge them much cheaper than medical doctors.

\section{Research Problems}

During our research, significant problems arose to us. The first thing, which requires us to pay more attention to these people, was that why Ilika people refer to traditional healers for so many times. It became clear that they refer to these healers in two stages. First, when the illness was at its very outset, that is to say, before Ilika people refer to the modern doctors, they visited traditional healers. The second stage was when they did not get any result from modern doctors and modern medicines, they will refer back to traditional healers. This was interesting for us to know what obstacles were before Ilika people or what their beliefs and interests were which pushed them to go and see traditional healers. For us, to know why Ilika people refer to traditional healers and healing as an alternative was of a great importance. These reasons made us become interested in the subject out of which we ended in many significant results that will be explained in their own parts.

We were also interested to know how people in this area perform their rituals and what different ways of treatment were. Moreover, we also wanted to investigate the roles of 
traditional healers in the treatment of the diseases in this zone. We understood that there are different types of traditional healings in Iran, specifically in Ilika tribes. Among all the problems we might come across, the most important ones are listed below:

1) To describe and analyze the traditional healing processes among Ilika tribes as one of the largest tribes in Garmsar. To know what traditional healing is and who traditional healers are.

2) To find and know the place of these healers and types of healing they perform and what they actually do during healing process among Ilika tribes.

3) To find out how Ilika people treat these traditional healers and their healings.

4) To discover the methods these healers use to heal and cure people.

5) To uncover why the services these traditional healers give to Ilika people are emphasized and are so important.

6) To see whether traditional healing methods are workable and applicable or not.

7) To explore the relationship between traditional medicine and modern medicine. Some older Ilika people claim that they have never been treated in a hospital. Some others prefer traditional healing yet another group utilize both traditional and modern medicine.

\subsection{Research Area}

\subsubsection{The City of Garmsar}

Garmsar, one of the major cities of Semnan is located in the west of the province. It is limited from north to Firooz Kooh and Damavand from west to Varamin and Qom, and it is from south to the desert of Esfahan province. The city has old water reservoir and shrines from Emamzadeh (Imam's son), Sham-sodin, Emamzadeh Esmail, Emamzadeh Ali Akbar, and Emamzadeh Abdollah. This city is very hot and dry in the summer, and very rainy and cold in the winter however most of the time, Garmsar is very hot and dry since it is located on the edge of the arid desert zone.

\subsubsection{Population and Education}

Primarily, Garmsar has a very large population estimated at around 68, 433 people. Its alternate names are Qeshlaq (or Qishlaq). The city is near the capital of the country which is Tehran $(82 \mathrm{~km}$. southeast). Moreover, Garmsar is located at a large plain while its surrounding villages are located near the many bunks of the river. Not only is the country known for many remaining historical places but also for its people who are educated and elite (Atlas of the World, 2006: 556).

In spite of the presence of the educated and the elites which are somehow famous in the whole Iran, the living of the people in Garmsar is still in poverty. In fact, there is a high dependency rate for poor households (Azghandian, 2005:109). Because of these conditions, the overall state of health of the people are affected. Indeed, the condition of the people is greatly shaped by the geographic location of the place. 
Consequently, the city of Garmsar is considered as a dry land because of its geographic location. Basically, the city is far from the Caspian Sea making it inaccessible to water. In addition, the city lies on the edge of the largest desert in Iran, which is the Dasht-e Kavir. The figure below shows the geographical location of the city of Garmsar.

\subsubsection{Geographical Location}

According to Ranjbar (1998: 6), Garmsar is a semi-desert region in southeast of Tehran. From the North, it is separated by the Alborz Mountain and is located on southern slopes. Also, the city is located northeast of the great desert of Iran. And due to geology and geomorphologic conditions, a semi desert climate dominates in this area.

Because of the geographical position of the city, it brings about a weather that is very hot and dry especially during the summer season (Iran Chamber of Commerce, Industries and Mines, n.d). So, the dry lands in the city significantly influence the way of life of the people especially in the health practices. The following maps, map of Iran and map of the city of Garmsar, might be useful for the readers of this thesis to know the exact location about which I am researching.

\subsubsection{Ilika Tribe People (Qome Ilikaee)}

Since the main focus of this dissertation is on Ilika tribes, it is necessary to know more about them and their location.

Ilika means borders and country. These Qome or tribes have settled themselves among different parts of Garmsar. Considering population, they are second just after another tribe called Osanloo. These Osanloos are believed to be from the North of Iran, a place called Shomal (means North) and Gilak, which means people of the North.

Ilika people' accent is believed to be similar to people of Damavand. The reason is guessed to be because there is an area in Mazandaran, an area in the North of Iran, which is called Ilika that is believed to be the place where Ilika people have been originated from. The time of their immigration is returned to Safavid period (Najmabadi, 1999: 531).

Mostly, through out the year, Ilika people were living on cattle rising and most of them lived in jungles and camps. They lived in the places called Qishlagh (warm place or winter-quarters) which were in their winter houses and in summer in country called Yelag (cool place or summer-quarters) little by little, they changed their style of living and settled in countries and started farming but also kept their cattle raising too. Previously, their population was 1200 families and their most important family include: Qasemi, Shah Hosseini and Aboli (Najmabadi, 1999: 581). Today, those semi-immigrants Ilikaee tribe consists of 251 families, which include 2534 men, and women of whom 796 are men and 738 are women. They are still keeping their Yelag (cool place or summer-quarters) and Qishlag (warm place or winter-quarters) and 71930 cattle's, which is mostly sheep's, and goats (Hosseini \& Aboli, 1999: 582).

The first and the foremost reason why I have picked up this area as my research site is that dry lands of Iran are considered as deprived areas. Since the economy of Iran is based on agriculture, apart from oil export, those dry lands which have less rain are among the poor 
economical areas. As a result, the access to modern medicine, which is definitely more expensive than traditional medicine, will be more difficult for them. On the other hand, the poor people of these areas approach traditional medicine and traditional healing because the medicine that the traditional healers advise the patients to take is cheaper and they can mostly be found in their own homes.

The second most important reason why I have chosen this area is that Ilika people have a nomadic life and most of the time on their ways to summer-quarters and winter-quarters they do not have access to modern medicine. But among the tribes, in those critical moments, the patients can find a person who knows traditional healing and the people of the tribes can trust him and use his/her methods to be cured.

Thus, these are the reason why I have chosen this area as my research site. Ilika tribes, like other parts of Iran, followed Zoroastrian, Jewish and other religions which were common at the time of Sassanides dynasty. It happened during the time when Islam was victorious in Iran. But in twenty second years of Hegira of the Prophet Mohammad (PBUH), when Omar was ruling, Muslims conquered Ray, Khar and Damghan. The people of the area later turned to Islam though (Asadi, 2002: 50).

\subsubsection{The Region of Ilika Tribes in Garmsar, Iran}

Garmsar, where in some part of it Ilika people live, is a city in the Semnan province of Iran, located about $82 \mathrm{~km}$ southeast of the capital city of Tehran. The distant between Garmsar and Tehran is about 107 kilometers. Garmsar is located in a large plain. The surrounding villages are located on the many bunks of the river Hibleh Rood, which is for irrigation. It lies on the edge of Dasht-e Kavir, Iran's largest desert. Many people in the city commute to Tehran due to its proximity. It had an estimated population of 68,234 in 2005. Garmsar is also known for its high population of the educated and elite. In order to get better understanding of the traditional healers of Ilika tribes in Garmsar, we firstly need to know their Geographical Position, Climate, History and Culture. (Elgood, 2005: 15).

\subsubsection{Geographical Location of Ilika Tribes}

The province of Semnan, which is mentioned before and Garmsar is part of it, covers an area of 96,816 square kilometers, to the east of which is Khorassan province, to the north are the provinces of Golestan and Mazandaran, to the west stand the provinces of Tehran and Qom, and to its south is Esfahan province. The various townships of the said province are, Semnan, Damqan, Shahrood and Garmsar. In the year 1996, the province had a population of about 501,000 of which $68.3 \%$ were in urban areas, and 31.7 were rural dwellers. In 1996, Semnan city (the capital of the province) had a population of 91,000, and the city of Shahrood, which accounts for being the largest city of this province, had a population of 105,000 .

The above-mentioned area is located in the southern skirts of the Alborz Mountain Ranges, with a downward gradient from north to south, ending at the deserted plain. The said province is divided into two,i.e., a mountainous region and the plains at the foot of the mountains. The former offers a scope for recreational activities as well as being a source for minerals. Whereas, the latter encompasses ancient cities of Iran (Najmabadi, 1999: 11). 


\subsubsection{Climate of the City of Garmsar}

The mountainous region of the province experiences a cold climate, whereas the mountain skirts and around the fringes of the desert are temperate and warm respectively. The city of Damqan, has cold weather in winter with moderate summers, being influenced by the strong northern rain bearing winds from Golestan and Mazandaran regions. The city of Garmsar experiences warm summers and moderate winters, Shahrood in its northern sector proves to be cold and in the central and southern regions temperate, and warm respectively. Furthermore, the city of Garmsar has extremely hot summers with comparatively cold, rainy winters, as this city is located in a dry and desert-like region.

\section{Significance of the Study}

Our paper and analyses of traditional healers among Ilika tribes will also contribute to an understanding of why and how traditional healing beliefs and practices continue to play an important role in contemporary Ilika tribes. The present essay, therefore, has the potential to make a significant contribution to the future study of Ilika tribes and their culture. Furthermore, the contribution of this study to the fields of traditional healing is based on the qualitative method. It also adds to the body of knowledge of traditional healing and traditional healers. Finally, these pieces of information provided here would be useful to the related fields mentioned above, as well as those of professional fields of traditional medicine.

\section{Research Methodology}

Methodology is very significant in conducting a research and choosing a suitable methodology is the most basic one. In this study, we used mainly an ethnographic method in addition to a qualitative method but the main focus is mostly on ethnographic method.

One of the main reasons why we chose an ethnographic method was that this method is that most distinctively associated with anthropology. It starts from the assumption that human activities are socially organized and so, from the outset, is committed to inquiring into patterns of interaction and collaboration. Unlike many other quantitative and qualitative methods in the social sciences which tend to use more formal instruments of data capture and analysis, the ethnographic method relies on an observer going into the field and 'learning the ropes' through questioning, listening, watching, talking, etc., with practitioners. We wanted to immerse ourselves into the work and its activities with a view to describing traditional healing and healers of Ilika tribes. One obvious consequence of this was that in the first instance, at least, data collected from Ilika people will be of the 'messy' and unstructured variety. It may include interviews, observations of work sequences, anecdotes, speculations, and so on. The data gathered, in other words, usually takes the form of field notes but is often supplemented by other sorts of data.

In addition to my ethnographic method we tried to get help from qualitative method for our research of which this paper tries to introduce intensive studies of cases and show in-depth understanding of the research as well as various human experiences concerning traditional healing in dry lands of Iran, especially in Garmsar. There will be few phases for this methodology of which in the first phase we try to identify the key informants of this research. 
Both traditional healers and patients will be the key informants since some patients are set to be interviewed by us.

Since this topic has not been studied in much depth it may provide insights to people who live in dry lands of Iran. Our research may benefit future researchers who prefer to study on the same subject and area of research, and medical anthropology as well as the healing and caring professions. It discusses, mainly, how traditional healing process happens and how traditional healers perform their healing performances. We have chosen qualitative method as one of the methods, which is used in this study because this method is designed to enable a researcher to understand people and the cultural context in which they live. We will try to introduce intensive studies of cases and show in-depth understanding of the research as well as various human experiences concerning traditional healing. Moreover, the significance of personal and cultural meaning and the centrality of me in gathering and analyzing data make this method of study essential. In sum, qualitative methodology is one of the methods which can accommodate different aspects of healing among Ilika people in our study. On the other hand, the rationality behind choosing qualitative method for this study was that it seeks to understand the participants' frames of reference and allows for an inductive understanding and awareness to emerge from the data (Taylor \& Bogdan, 1998: 30). A researcher must be flexible and self-aware so as to allow the themes from the data to emerge and speak for themselves. Such a methodology allows for the consideration of participants as holistic individuals, with mental, emotional, physical and spiritual aspects, which is consistent with a holistic healing perspective.

Traditional healing and healers are under-researched. This is both a curse and a blessing for traditional healing and healers of Ilika people. The problem with a lack of research on cultural healing traditions is that the knowledge stands a good chance of dying out or being lost. The blessing, of course, is that the knowledge remains sacred and is easier to protect from those who might seek to exploit ceremonial practices, medicines and relationships for profit.

Exploring the views and experiences of traditional healers requires an intimate, respectful and reflexive methodology that does not reduce the participants to variables to be studied. Deeply intimate and personal interviews are required that capture the richness and complexity of the reality of those individuals. For these reasons, a qualitative methodology was employed in an effort to produce richly descriptive data about traditional healing and traditional healers among Ilika people.

Taylor and Bogdan's (1998:30) approach to qualitative inquiry is connected with developing in-depth understandings of phenomenon from the participant's point of view. We were interested in understanding the meaning that people give to their experiences, rather than assigning my meaning to those experiences.

Our primary task was to collect data by interviewing informants of the area. The followings are among the interviewed people:

1) Tribal elders who have inherited and kept alive traditions from the ancient time to now. 
2) The first generation of Ilika tribes who witnessed the transition from a traditional to a simple modern society.

3) The second generation of Ilika people who were totally forbidden by their parents to have anything to do with traditional customs.

4) The present generation who are exploring ways of incorporating traditional practices into their lives.

5) Shafaa Dahandegan (the term is usually translated into English by "Traditional healers").

In addition to extensive interviews, we attended as many traditional ceremonies as we could; ceremonies, festivals, traditional healing ceremonies, prayer meetings, wedding ceremonies, burial services and so on. We have been blessed with the opportunity to participate in these ceremonies with much enthusiasm because it was both interesting and fun. However, actually living and working with the people in this community has made our dream come true. It was everything we were expecting and more. We would not trade those periods weeks for anything. It actually, prompted us to ask more questions from the Ilika people and learn even more due to our lack of knowledge. However, that is what this is all about, living and learning. The best way to learn is to ask. We attended as many of these gatherings as we could most of the weekends. It was a wonderful experience. There were so many talented people there and the songs and dances were very uplifting. One important lesson we learned there was that when you want to pray you have to focus on what you recite! We think the highlight of our stay was being able to do a sweat at the sweat lodge. This is a very empowering ceremony where the act of prayer combined with intense heat is used to cleanse the mind body and soul. We left the sweat feeling like new people and the only regret we have is that we did not get the chance to do any more sweats. Even more reason for us to return sooner than later. Our goal during this trip was to learn as much as we could about traditional healing, healers medicine. As a result, we spent the majority of our time in and around the Ilika people. We were fortunate to find some friends to help and teach us a lot about healing, healers, medicine and so on. The more people we befriended the more valuable lessons in life we were taught. We also learned a lot about ourselves. Most importantly, we learned that we are always learning no matter how old you are and everyone has some knowledge to offer.

Although the time we spent there was brief, we can proudly say with confidence that we feel we have been accepted as an honorary member of this community. We want to thank all of those who welcomed us into their homes and were eager to share their knowledge.

Our intimate and close relationship with Ilika tribe and culture enriched our descriptive analysis. Being among the tribal groups and teaching at the university near the area we were teaching enabled us to collect much more data through interviews with the healers and elders who still remembered traditions. By having these interactions and applying the perspective of one who knows the culture from the inside, she has thus been able to provide a more detailed study than previous studies of the Ilika tribe, the majority of which have been done by outsiders. 


\section{Macrothink}

Based on the above explanation, the qualitative research method is particularly well suited to the needs and objectives of this paper. Multi-method in practice, qualitative research is designed to enable us to understand people and their cultural in which they live (Denzin, 2004: 15; Hanida, 2008: 130). In particular, qualitative methodology is significantly open ended to accommodate the divergent elements of traditional healing and healers of Ilika tribes. Moreover, by exploring and employing the qualitative method of conducting research we would better be enabled to understand the nature of traditional healing and healers in Garmsar, Iran, especially among the Ilika tribes. Furthermore, by using qualitative method for the research, we will try to introduce intensive studies of cases and show in-depth understanding of the research as well as various human experiences concerning traditional healing. There will be four phases for this methodology of which in the first phase we try to identify the participants of the research. Concerning this study, both the traditional healers and patients will be the participants since some patients are set to be interviewed by us.

The following pictures were taken by us among the people of Ilika tribe who kindly helped us. 


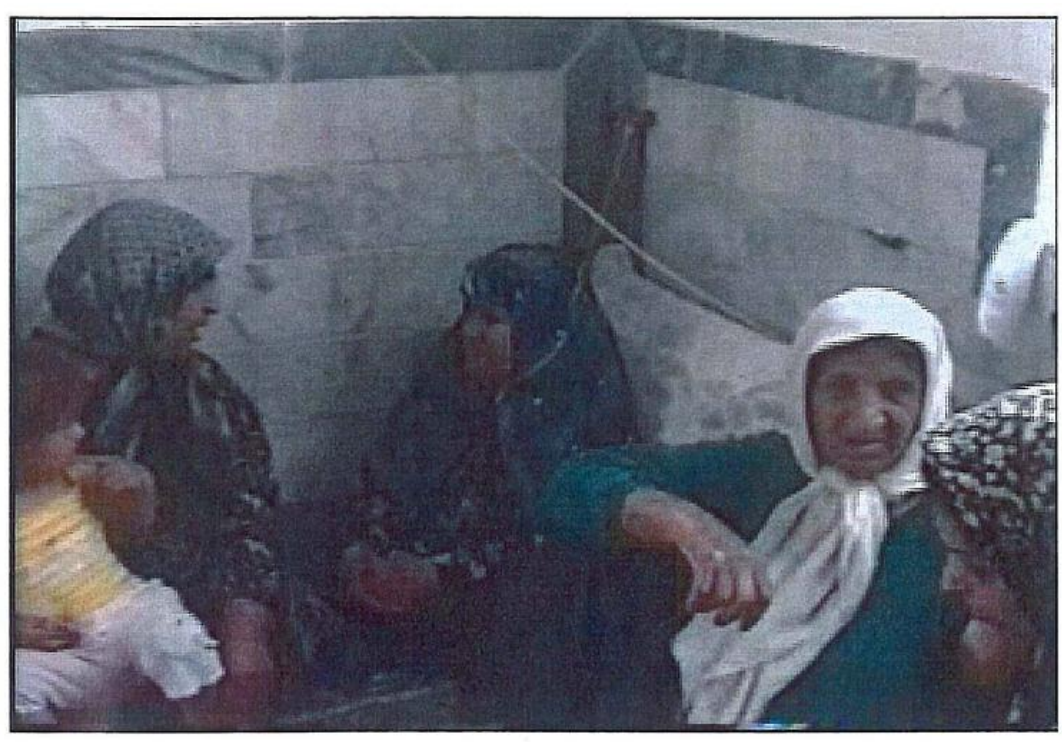

مصاحبه با خانمهاى كهنسال

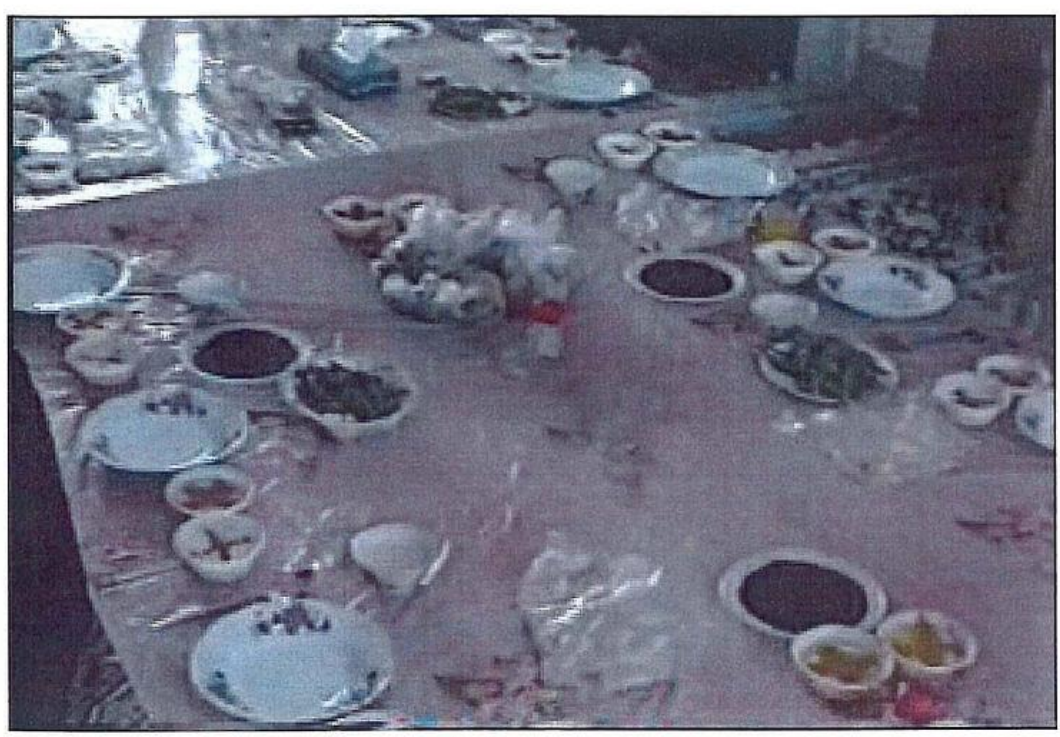

سفره حضرت ابوالفضل

Figure 3.

Thus, the qualitative research framework closely matches the present research goals and style. The importance of cultural meaning, personal meaning, and the centrality of us in the intimate experience of data collection/reception in this project makes qualitative methodologies essential.

In the second phase of the methodology, we tried to see the real thing, which means that we will be present in the research process and attempts to observe closely the actual process of healing. The third phase would be the analysis of the research data collected from the first phase and the actual experience during the second phase. 


\section{Macrothink

Lastly, the final phase will ensure the ultimate translation and interpretation of the data gathered from the informants and respondents.

Moreover, in this paper, we want to show how things are used as healing and healers' instrument or how they work among Ilika tribes (Qome Ilikaee) context or how that functional phenomena help to heal different diseases.

In addition to the above remarks, we attended the following ceremonies among Ilika tribes:

Ilika people gatherings and ceremonies where people try to recapture the past through traditional services

1) Traditional festivals

2) Traditional naming ceremonies

3) Traditional prayer ceremony

4) Traditional healing ceremonies

5) Mosque Friday services

6) Prayer meetings

7) The Holy Quran study groups

8) Burial services

9) Mosque wedding ceremonies

Thus, the qualitative approach was chosen as the methodology for this paper by providing relevant explanations, interpretations, predictions, and applications about the phenomenon in question.

\section{Research Questions}

We have used qualitative method of research in this study and want to explore traditional healing and healers among Ilika people. The main agenda in this research is to know why the traditional healing is still relevant to the Ilika people. In order to clarify this main question, these are the research questions that this paper seeks to address:

1) How popular is traditional healing among the people of Garmsar?

2) What are the characteristics of the traditional healers in Garmsar, among Ilika tribe, Iran?

3) How do traditional healers perceive healing? What is their understanding of this concept?

4) What are the techniques used by the traditional healers in providing cures for people's illnesses?

5) How do different traditional healers perform healing?

6) What happens during healing? 


\section{Research Aims and Objectives}

Our research aims at investigating the traditional healing and healers of Ilika tribes of Garmsar, Iran and mainly intends to provide new insights on the traditional healers among the Ilika tribe. Our research specifically aims at:

1) Identifying, analyzing, and explaining how popular traditional healing among the people of that society and what the characteristics of the traditional healers among Ilika tribes are.

2) Understanding the way the healers perceive healing process or recognizing and focusing the alternative concept of using traditional medicine among Ilika people.

3) Investigating the numbers and types of healers, their training and the healing process and examining the role of healers over time and space.

4) Exploring a comprehensive study on traditional healing and providing information with which practitioners and other healers in other parts of Iran can facilitate their success in various contexts.

5) Intending to assist researchers by providing pieces of information for their future investigations.

Our research, therefore, attempts to mainly focus on Ilika tribes (Qome Ilikaee) who live in Garmsar. It is noteworthy to remind the readers of my paper that these people cannot reach modern medicine easily since the medical centers in Garmsar, which is the nearest area to Ilikans, is not quite close to them. Furthermore, modern medicine is expensive in Iran and since most of Ilika people (Qome Ilikaee) are leading a poor life and live under poverty line. So, they could not afford using modern medicine and as a result, traditional healing and medicine is an alternative for them. Moreover, they are not usually supported by governmental insurance and, consequently, they prefer or have to choose traditional medicine to modern medicine. In sum, traditional medicine and traditional healing is an alternative and complementary option for the people of the area since the majority of the people cannot afford to pay the modern doctors.

\section{Conclusion}

The paper project stemmed from recognition of lack of knowledge and understanding of traditional healing and traditional healers of Ilika tribes of Iran. Its major intention is to share traditional healing knowledge in a good way with an academic audience as a beginning effort to bridge the large cultural division between native and non-native Iranians. We are quite close to indigenous people of the area and this helped us toward a better understanding of a cultural phenomenon. This cultural phenomenon is traditional healing. While this research has also been about personal growth and understanding the self, it began and remains about the growth and development of indigenous literature.

The ethnographic and qualitative study sought to get better understanding of traditional healing by and for native Iranian people. The research design involved in-depth interviews of few (mention how many) practitioners of traditional healing. The interview questions, (please 


\section{Macrothink

refer to the attached appendix), unveiled a rich understanding of what practices are involved, the rationale for these practices, important characteristics and strategies of the healers, and how these healers believe traditional healing works.

\section{References}

Denzin, K. N., \& Lincoln, S. Y. (Eds.). (2000). Handbook of Qualitative Research (2nd ed.). Thousand Oaks, California.

Ember, C. (Ed.). (2004). Encyclopedia of Medical Anthropology: Health and Illness in the World's Cultures. New York: Springer.

Geertz, C. (1983). Local Knowledge. New York: Basic Books, Inc., Publishers.

Hakim, M. (1986). Eating and Drinking Stuffs from Religious. Tehran: Islamic cultural.

Kaufmann, S., Sher, A., \& Ahmed, R. (2003). Immunology of Infectious Diseases. ASM Press.

Mimi, H. (2008). Roses among Thorns: The Emergence and Expansion of Contemporary Female Muslim Da'ies in Malaysia. A PhD Thesis.

Ranjbar, E. (1998). Sulfate Exploiters and Factors Affecting Emerging of Sodium Sulfate Layer in Margin of Desert: A case Study of Garmsar, Iran. Theme 9: Sustainable Development of Oasis; Desert Communities and Socioeconomic Studies; and Role of NGOs. p. 6.

Shah Hoseini, A., \& Aboli, S. (1999). Ilikan's proverbs. Tehran: Naghshe bayan.

Tabibi, H. (1998). Tribal Sociology. Tehran: University of Tehran.

Taylor, S. J. (1998). Commentary of Constructing a Psychology of Teaching and Learning. In K. Seifert (Ed.), Constructing a psychology of teaching and learning. Boston: Houghton Mifflin.

\section{Copyright Disclaimer}

Copyright reserved by the author(s).

This article is an open-access article distributed under the terms and conditions of the Creative Commons Attribution license (http://creativecommons.org/licenses/by/3.0/). 